(c) American Dairy Science Association, 2007.

\title{
Synchronization of Estrus and Pregnancy Risk in Anestrous Dairy Cows After Treatment with a Progesterone-Releasing Intravaginal Device
}

\author{
R. B. Walsh, ${ }^{\star 1}$ S. J. LeBlanc, ${ }^{\star}$ T. D. Duffield, ${ }^{\star}$ D. F. Kelton, ${ }^{\star}$ J. S. Walton, $†$ and K. E. Leslie* \\ *Department of Population Medicine, and \\ †Department of Animal and Poultry Science, University of Guelph, Guelph, Ontario, Canada, N1G 2W1
}

\begin{abstract}
Lactating Holstein cows (located in 4 dairy herds) that had failed to display estrus as defined by increased pedometer activity by $63 \pm 3 \mathrm{~d}$ in milk, were enrolled to investigate the effect of a progesterone-releasing intravaginal device (PRID, $\mathrm{n}=268$ ) relative to a placebo intravaginal device (PID, control, $\mathrm{n}=266$ ) on days from device removal to artificial insemination (AI), the probability of pregnancy at first AI, and days from device removal to pregnancy. Cows were assigned randomly to receive a PRID or PID for $7 \mathrm{~d}$ and an injection of $\mathrm{PGF}_{2 \alpha}$ at device removal. Upon device removal, a vaginitis score was assigned and AI occurred at observed estrus. Cows failing to display estrus within $14 \mathrm{~d}$ of device removal were subjected to a subsequent reproductive exam and were treated with $\mathrm{PGF}_{2 \alpha}$. Two percent of PRID-treated cows and $11 \%$ of control cows displayed estrus during the 7-d exposure period. Among the remaining cows, $93 \%$ of the devices were present at the scheduled removal. Cows treated with the PRID were $60 \%$ less likely to have purulent debris on the device than control cows. Vaginal reaction, however, was not associated with any of the reproductive outcomes. Investigation of the reproductive outcomes revealed a treatment $\times$ parity interaction. Progesterone-treated primiparous cows were inseminated $17 \mathrm{~d}$ earlier, with no significant change in the probability of pregnancy at first AI ( 30.3 vs. $42.0 \%)$, and no difference in median time from device removal to pregnancy (52 vs. $53 \mathrm{~d}$ ) relative to control primiparous cows. Conversely, PRID-treated multiparous cows were inseminated $8 \mathrm{~d}$ earlier, with no change in probability of pregnancy at first AI (24.6 vs. $18.8 \%$ ); however, median time from device removal to pregnancy was reduced by $20 \mathrm{~d}$ ( $67 \mathrm{vs.} 87 \mathrm{~d}$ ). These results support the efficacy of a PRID to induce estrus in previously anestrous cows. The reason, however, for the variable response between primiparous and multiparous cows was not clear.

Key words: progesterone-releasing intravaginal device, synchronization, fertility, time to pregnancy
\end{abstract}

Received June 6, 2006.

Accepted October 12, 2006.

${ }^{1}$ Corresponding author: rwalsh@uoguelph.ca

\section{INTRODUCTION}

Systematic reproductive management programs are increasingly being applied on modern dairy farms. These programs permit control of time to first $\mathrm{AI}$ and reduction or elimination of detection of estrus (Pursley et al., 1997; Cartmill et al., 2001). Controlling time to first service must balance potential pregnancy risk (Stevenson and Phatak, 2005) with the associated cost per day open incurred in cows failing to conceive between 85 and 120 DIM. Numerous studies have reported a significant reduction in first-service pregnancy risk and increased time to pregnancy in cows having low circulating progesterone concentrations at initiation of a timed AI protocol (Cartmill et al., 2001; Gumen et al., 2003). Reduction in pregnancy risk is exaggerated among cows diagnosed as anovulatory at the start of an ovulation-synchronization protocol (Gumen et al., 2003); however, few North American studies have selectively treated cows at risk for anovulation.

Thatcher and Wilcox (1973) were the first to report that failure to display estrus before the end of the voluntary waiting period was predictive of future reproductive failure. Cows diagnosed as anestrous include cows that fail to ovulate and those that ovulate in the absence of behavioral estrus. Diagnosis of anovulatory anestrus is dependent on repeated serum or milk progesterone analysis; however, this is rarely performed in on-farm situations. Instead, hormonal therapies are applied uniformly to all animals regardless of ovarian function (Cartmill et al. 2001; El-Zarkouny et al. 2004), acknowledging the likelihood of failure to respond among anovular cows.

Anovulatory anestrus occurs in 10 (Lamming and Darwash, 1998) to 64\% (El-Zarkouny et al., 2004) of lactating dairy cows, with a mean of $20 \%$ from around the world (Opsomer et al., 2000). Although cows that fail to ovulate are not the only population of cows that suffer from decreased probability of pregnancy at first AI, prolonged time to pregnancy, and increased risk of culling, anovulation accounts for the major failure (Lamming and Darwash, 1998).

Progesterone supplementation in anovulatory anestrous cows reestablishes the hypothalmic responsiveness to estradiol produced by the developing domi- 
nant follicle. Reestablishing hypothalamic-ovarian communication permits the characteristic LH surge in response to elevated estradiol concentration that is required for ovulation of the dominant follicle. In addition, progesterone supplementation increased estradiol responsiveness in behavioral centers of the brain, thus increasing the probability of displaying behavioral estrus at the first postpartum ovulation (Rosenberg et al., 1990; Fike et al., 1997), increasing the probability that the subsequent luteal phase would be of normal duration, and increasing pregnancy risk after ovulation synchronization protocols (Folman et al., 1990; Lucy et al., 2001).

The objective of our study was to investigate the effect of administering progesterone to lactating dairy cows that had failed to display estrus during the first $20 \mathrm{~d}$ of the breeding period on days to AI at observed estrus, probability of pregnancy at first AI, and time from end of progesterone treatment to pregnancy. Our hypothesis was that progesterone supplementation in cows failing to display estrus, measured by pedometry, would improve synchronization of estrus and first-service pregnancy risk, and decrease total days open relative to anestrous cows not receiving progesterone supplementation.

\section{MATERIALS AND METHODS}

This study was conducted between May 2003 and October 2004 using lactating dairy cows from 4 commercial free-stall dairy herds in Ontario, Canada. These herds were selected based on the herd managers' use of an automated estrus-detection system and their willingness to participate. Study herds milked 100, 120, 240, and 340 cows thrice daily.

Parity and season of calving (fall: September through November; winter: December through February; spring: March through May; summer: June through August) were recorded. Occurrences of retained placenta (failure to pass the fetal membranes by $24 \mathrm{~h}$ after parturition), or metritis (uterine infection producing systemic illness) in the current lactation were also recorded.

To characterize enrolled cows relative to cycling herdmates, predictors of energy status during the peripartum period including circulating ketone body concentration and body condition were monitored. A semiquantitative milk ketone test (KetoTest, Elanco Animal Health; Guelph Ontario, Canada) validated for BHBA (Geishauser et al., 2000) was used once during the first week and again during the second week postpartum. Body condition scores were assigned to each cow using a quarter-point scale from 1 to 5 (Ferguson et al., 1994). Each cow was scored during the week before expected calving and again at enrollment (60 to $66 \mathrm{DIM}$ ). Analysis was performed using BCS as an indicator variable, such that cows were classified as thin $(\leq 2.5)$, fair $(\geq 2.75$ to $\leq 3.5)$ or fat $(\geq 3.75$ ) at each of the 2 sampling periods and effect of change in BCS was compared among cows that lost $>1$ point relative to cows that lost $<1$ point.

Pedometry was used for detection of estrus on all 4 farms (AfiAct System, Germania Dairy Automation, Waunakee, WI, or Westfalia-Surge Individual ID and Pedometer, Mississauga, ON, Canada). Pedometers are small $(10 \times 20 \mathrm{~cm})$ electronic transducers with a mercury switch encased in a waterproof plastic shell. The device served as an electronic individual cow identifier as well as recording the number of steps taken. They were placed above the fetlock on a hind leg. The pedometer information recorded by the device was transmitted to the herd management software (Afimilk 3.02A, Afikim Israel; Dairy-Plan 5.0, Westfalia-Surge) at each of 3 daily milkings through a transponder located at each milking stall. Herd management software automatically compared the current pedometer measurement with the previous 10-d average within cow. Cows that exceeded their previous 10-d average step count by $90 \%$ were assumed to be in estrus.

Those cows exceeding the voluntary waiting period (40 DIM) by $21 \mathrm{~d}$ and not inseminated became eligible for enrollment. Once weekly all postpartum cows not yet inseminated and between 60 and 66 DIM were enrolled. Cows diagnosed with disorders of the reproductive tract including uterine or ovarian adhesions, pyometra (distended uterine horns with echoic material visible in the horns on ultrasound examination), or identified to be culled were excluded from the study. Cows were assigned randomly to 1 of 2 treatments. Devices were assigned randomly to each herd in groups of 10 to ensure an equal number of treatment and control cows within each herd; herd managers and veterinarians were blind to treatment assignment. The treated group received a progesterone-releasing intravaginal device (PRID; Vétoquinol, Lavaltrie, Quebec, Canada) and the control group received a placebo intravaginal device (PID; Vétoquinol). The PRID consisted of a silastic coil impregnated with $1.55 \mathrm{~g}$ of progesterone. The PID was constructed of the same silastic coil without progesterone and was visually indistinguishable from the PRID. Before device insertion, the vulva was washed with warm water and dried with a clean towel. A small amount of antibacterial lubricant was applied to the device before insertion. Choice of antibacterial lubricant was according to herd preference and included products that contained chlorhexidine (Hibitane Veterinary Ointment; Ayerst Veterinary Laboratories, Guelph, ON, Canada), tetracycline, or iodine. Enrollment criteria were expanded to include cows enrolled in the protocol $1 \mathrm{wk}$ early and $1 \mathrm{wk}$ after the specified enrollment criteria to account for variability in 
herd visits. This expanded enrollment window included cows enrolled between 53 and 73 DIM.

Cows displaying estrus during treatment had the device removed and were inseminated. Cows identified in estrus on all 4 farms at the morning milking were inseminated immediately, whereas those displaying increased activity at the afternoon or evening milking were inseminated after the next morning milking. Seven days after insertion, the intravaginal device was removed and 500 $\mu \mathrm{g}$ of $\mathrm{PGF}_{2 \alpha}$ analog (cloprostenol sodium; Estrumate, Schering-Plough Animal Health, Pointe Claire, QC, Canada) was administered by i.m. injection. A vaginitis score (VS) was assigned at device removal $(0=$ no debris; $1=$ small flecks of purulent debris on the device; $2=$ copious amounts of purulent debris on device and vulva).

After device removal, cows were inseminated based on increased pedometry activity. Cows not inseminated within $14 \mathrm{~d}$ after device removal were then subjected to the herd's regular reproductive evaluation and therapy. A second injection of $\mathrm{PGF}_{2 \alpha}$ was the most frequently applied intervention when cows had not displayed estrus. Cows that failed to return to estrus after AI were examined for pregnancy 28 to $37 \mathrm{~d}$ post-AI by using transrectal ultrasonography (Medison Sonovet 2000; Universal Medical Systems Inc., Bedford Hills, NY). Visualization of a fluid-filled horn and the presence of a conceptus were positive indicators of pregnancy. Visualization of anechoic fluid alone was not considered a positive diagnosis, and these cows were reexamined at the following herd visit. Pregnancy loss was monitored passively; cows displaying increased estrous activity and cows inseminated after initial pregnancy diagnosis were reexamined by palpation per rectum. Only pregnancies carried full term or those still viable on August 31, 2005, were used in the final analysis. Cows diagnosed not pregnant were subjected to the herd-specific veterinary reproductive evaluation and therapy including $\mathrm{PGF}_{2 \alpha}$ and ovulation synchronization protocols (Ovsynch; Pursley et al., 1997).

Reproductive performance was assessed using the interval from device removal to first AI, probability of pregnancy at first $\mathrm{AI}(\%)$, and time from device removal to pregnancy. Cows were excluded when they were coded as not eligible for $\mathrm{AI}$ and when the day of device insertion was outside the accepted range as specified in the enrollment criteria. All records were monitored for at least 10 mo after enrollment. For survival analysis, cow time at risk was accumulated until the event of interest (AI or pregnancy) occurred. Cows that failed to record the event of interest (AI or pregnancy) were censored at the first of 4 events: 1) more than 2 consecutive estrous periods determined by pedometry in the absence of AI; 2) coded as not eligible for AI; 3) removal from the herd; or 4) August 31, 2005.

\section{Data Management and Statistical Analysis}

All analyses were performed with Intercooled Stata 9.1 (Stata Corp., 2005, College Station, TX). Simple treatment comparisons were made using the $\chi^{2}$ statistic. Count data were analyzed using Poisson regression. Multinomial logistic regression was used to evaluate the odds of a vaginal reaction between control and PRIDtreated cows. Final models of dichotomous outcomes, including covariates, were generated using multivariable logistic regression. Effect of correlation of cows within a herd (clustering) was adjusted for in both the binary and count models by using generalized estimating equations with compound symmetry correlation structure to produce robust standard errors.

Time from device removal to first AI was estimated using a Kaplan-Meier life-table to account for treated cows that accumulated time at risk, but were not inseminated. Kaplan-Meier (product limit) survival function estimates were used to calculate crude associations of treatment with median time from device removal to first $\mathrm{AI}$ and to pregnancy, as well as to generate a graph of cumulative pregnancy risk over time. The restricted mean and 95\% confidence limits were determined the first time the survival function was $\leq 0.5$. Effects of treatment on time to pregnancy were analyzed with multivariable survival analysis using Cox's proportional hazards regression. The Cox proportional hazard model measures the probability of pregnancy per unit time expressed as a hazard ratio. Robust standard errors were generated to account for clustering.

Main effects of interest were the impact of treatment on the probability of pregnancy at first AI and time from device removal to pregnancy in cows failing to display estrus by $8 \mathrm{wk}$ postpartum. The probability of pregnancy at first AI was initially investigated independent of time from device removal. Subsequently, analysis of the probability of pregnancy at each of the first 3 cycles was performed by retrospectively categorizing cows based on treatment synchronization. First cycle included cows inseminated within $14 \mathrm{~d}$ of device removal. Second cycle included first AI for cows inseminated for the first time more than $14 \mathrm{~d}$ after device removal and the second AI for cows synchronized by progesterone therapy. Third cycle was composed of second AI among nonsynchronized cows and third AI among cows inseminated within $14 \mathrm{~d}$ of device removal. In all cycles the denominator excluded pregnant cows and cows that were culled without that AI. Median time from device removal to AI in the second and third cycle was estimated using the Kaplan-Meier survival function. In addition to the main effect of treatment, effects of parity and season of calving were offered to the model as covariates. These models were built by manual backward stepwise elimination, 
removing the covariate with the largest probability value at each step, until only significant $(P<0.10)$ covariates remained. If 1 level of an indicator variable was significant, all levels were retained. Two-way interactions were assessed among significant variables by generating a cross-product term. Significance of interaction terms were assessed based on the Wald test statistic of the interaction term, and a likelihood ratio test was applied to permit comparison of the entire model with the interaction term relative to the model without the interaction term. If both tests indicated the significance of the interaction term and its inclusion improved the fit of the model, a categorical variable was created in the logistic regression model of first service pregnancy risk and the Cox proportional hazard models of time from device removal to AI and time to pregnancy. This modeling strategy permitted direct comparison of within and between parity groups. Significant differences among categorical variables were assessed using the Wald postestimation statistic.

To investigate the potential impact of differential culling risk between parity and treatment groups, the assumption of independent censoring was assessed through complete positive (all cows pregnant at time of censoring) and complete negative censoring (censored cows failed to become pregnant for $350 \mathrm{~d}$ after device removal). The proportional hazard assumption was assessed graphically using a log-cumulative hazard plot.

\section{RESULTS}

During the study, 48\% (127/268), 41\% (58/141), 38\% (264/694), and 59\% (85/143) of all cows calving failed to display estrus by $60 \mathrm{DIM}$ on farms 1 to 4 , respectively. No significant differences were detected in the prevalence of retained placenta or metritis among farms. Cows having a retained placenta were 2 times more likely to be enrolled in the study relative to cows inseminated before 60 DIM (6.7 vs. $3.2 \% ; P=0.005$ ). Prevalence of metritis in cows enrolled in the study, and those inseminated before 60 DIM, did not differ (3.2 vs. 3.1\%).

A milk ketone test was performed on $60 \%(754 / 1,246)$ and 56\% $(698 / 1,246)$ of all cows during the first and second week postpartum, respectively. Prevalence of subclinical ketosis $(\geq 100 \mu \mathrm{mol}$ of BHBA/L of milk) did not differ between cows enrolled and those inseminated before 60 DIM (wk $1=32.7$ vs. $37.1 \%$; wk $2=35.5$ vs. $36.1 \%)$. Because of the double-blind assignment method, PRID-treated cows were $40 \%$ less likely to have been classified as ketotic in the first week after calving $[\mathrm{PRID}=27 \%$ vs. control $=40 \%$; odds ratio $(\mathbf{O R})=0.56$; $P=0.03]$.

Distribution of BCS before calving between cows enrolled in the study and those inseminated before 60 DIM was: thin $=1$ vs. $0.9 \%$; fair $=57.9$ vs. $55.7 \%$; fat $=41.1$ vs. $43.4 \%$. Of cows enrolled, greater than $80 \%$ of cows had a BCS $\leq 3$ at 60 DIM. Five cows had a BCS $\geq 3.75$ at enrollment. A total of $33.5 \%$ of cows lost 1 BCS point between calving and treatment [PRID $=37.6 \%$; 95\% confidence interval $(\mathbf{C I})=28$ to $46 \%$; control $=22.9 \%$; $95 \% \mathrm{CI}=19$ to $38 \%$, respectively].

In total, 534 devices (268 PRID and 266 control) were used. Retention rate was $93 \%$ for both treatment and control devices. Retention was not influenced by farm, season of calving, or parity. Controls were 5.4 times more $(P=0.001)$ likely to display estrus with the device in place than PRID-treated cows (11.6 vs. $2.0 \%$; $95 \% \mathrm{CI}=$ 2.3 to 14.7). The proportion of cows displaying estrus during treatment was not influenced by parity [primiparous $=7.1 \%(14 / 196)$ vs. multiparous $=5.9 \%(20 / 338)$; $\mathrm{OR}=1.2, P=0.6]$. Fifty-five cows were excluded because they were outside the DIM criteria, they were designated not to be bred before device insertion, or they had previously been inseminated. After exclusion, 218 PRID and 192 control cows remained for analysis. A total of $85.3 \%$ (186/218) of PRID-treated cows and 74.5\% (143/192) of control cows were pregnant at the end of the study. Fifteen cows (10 control and 5 PRID) failed to show any increase in pedometry activity after device removal, and before exiting the herd. A further 27 PRID and 32 control cows were culled after a diagnosis of nonpregnancy, and 3 nonpregnant control cows remained in the herd as of August 31, 2005. Five percent of cows (21/410) were passively identified as having pregnancy loss subsequent to pregnant diagnosis at first AI.

A VS was recorded for $86 \%$ of devices (352/410). No vaginal reaction to the device was recorded in $50 \%$ of control and 57\% of PRID-treated cows. Treatment had no impact on the odds of a minor vaginal reaction (VS = 1 ; $\mathrm{PRID}=34.2 \%$, control $=32.9 \%$; OR $=0.9, P=0.6$ ). Cows receiving the PRID, however, were $60 \%$ less $(P<$ 0.001 ) likely to have copious amounts of cloudy mucus on the device at removal (VS $=2$; PRID $=7.7 \%$ and control $=17.2 \%$ ). Accounting for the impact of clustering at the herd level, the difference in VS was not influenced by parity, season, or periparturient disease.

Mean time postpartum at device insertion was $63 \pm$ $3 \mathrm{~d}$ for both groups. A total of 182 controls and 213 PRIDtreated cows were inseminated once. Overall, progesterone treatment reduced $(P=0.003)$ the time from device removal to AI. Accounting for the effect of clustering at the herd level, among primiparous cows, PRID treatment reduced time from device removal to AI by $17 \mathrm{~d}$ $[$ median $=3 ; 95 \% \mathrm{CI}=3$ to 4 ; hazard ratio $($ HR $) 1.7 ; P$ $<0.001]$ relative to control primiparous cows (median $=$ 20; 95\% CI $=6$ to 24). The PRID-treated multiparous cows were inseminated $8 \mathrm{~d}$ earlier $(P<0.001)$ than were 
Table 1. Final Cox proportional hazard model for the time (days) from device removal to first AI of 410 lactating Holstein cows that failed to display estrus, as measured by pedometry, between 39 and 60 DIM treated with a progesterone-releasing intravaginal device (PRID) or placebo intravaginal device (control) for $7 \mathrm{~d}$ and injected with $\mathrm{PGF}_{2 \alpha}$ at removal

\begin{tabular}{|c|c|c|c|c|c|c|}
\hline Parity & Treatment & $\mathrm{n}$ & $\mathrm{AI}^{1}$ & $\begin{array}{c}\text { Hazard } \\
\text { ratio }\end{array}$ & $P$-value & $\begin{array}{c}95 \% \\
\text { CI }\end{array}$ \\
\hline Primiparous & PRID & 79 & $3^{\mathrm{a}}$ & 1.7 & $<0.001$ & $1.5-1.9$ \\
\hline Multiparous & $\begin{array}{l}\text { Control } \\
\text { PRID } \\
\text { Control }\end{array}$ & $\begin{array}{r}77 \\
139 \\
115\end{array}$ & $\begin{array}{r}20^{\mathrm{b}} \\
5^{\mathrm{c}} \\
13^{\mathrm{b}}\end{array}$ & $\begin{array}{c}\text { Referent } \\
1.3 \\
\text { Referent }\end{array}$ & $<0.001$ & $1.2-1.3$ \\
\hline
\end{tabular}

${ }^{a, b}$ Different letters within a column represents significant difference using a Wald postestimation test $(P<0.05)$.

${ }^{1}$ Median time (days) from device removal to first insemination.

control multiparous cows (Table 1). The daily probability of AI was not different between control primiparous and multiparous cows $(\mathrm{HR}=1.04, P=0.16 ; 95 \% \mathrm{CI}=0.98$ to 1.1$)$.

Overall, the PRID-treated cows were 2.1 times more $(P<0.001)$ likely to be inseminated within $14 \mathrm{~d}$ of device removal than control cows. The synchronization effect was greater $(P<0.001)$ in PRID-treated primiparous cows, but was not different $(P=0.15)$ among multiparous cows relative to the parity-specific controls (Table 2). Comparing the estrus-synchronization rate across parities, PRID-treated multiparous cows were less likely $(P=$ 0.03 ) to display estrus within $14 \mathrm{~d}$ of device removal than PRID-treated primiparous cows, whereas there was no significant difference in synchronization rate between control multiparous and primiparous cows $(\mathrm{OR}=0.6$; $P=0.14 ; 95 \% \mathrm{CI}=0.4$ to 1.2 ). Probability of displaying estrus within $14 \mathrm{~d}$ after device removal was not significantly associated with farm, season, VS, or any potential 2-way interactions.

Overall, the probability of pregnancy at first AI did not differ between the PRID and control cows (25.8 vs. $28.6 \%$, respectively). Treatment, parity, season of calving, VS, retained placenta, metritis, and ketone information from the first and second week postpartum were offered to the model. Multiparous cows were less $(P=$ 0.004 ) likely to be diagnosed pregnant to the first AI relative to primiparous cows. Introduction of a treatment $\times$ parity interaction term into the model tended to be significant (Wald test; $P=0.07$ ). A likelihood ratio test was applied to evaluate the overall significance of the interaction term to the model. This evaluation supported the hypothesis that the interaction term added $(P=0.06)$ information to the model.

Independent of time from device removal, and controlling for the correlation of cows at the farm level, within parity $\times$ treatment group did not alter the probability of pregnancy at first service (primiparous PRID vs. control $\mathrm{OR}=0.6, P=0.13$; multiparous PRID vs. control $\mathrm{OR}=$ $1.4, P=0.3)$. Two-way interaction terms for treatment and ketone status in wk 1 and VS were not significant in a model to assess the impact of treatment on risk of pregnancy at first service.

Among cows inseminated within $14 \mathrm{~d}$ of device removal, the probability of pregnancy at first AI was 27.9,

Table 2. Probability of pregnancy diagnosed 28 to $37 \mathrm{~d}$ after insemination performed once per day after observed estrus, as measured by pedometry, in 395 lactating Holstein cows that failed to display estrus between 39 and 60 DIM treated with a progesterone-releasing intravaginal device (PRID) or placebo intravaginal device (control) for $7 \mathrm{~d}$ and injected with $\mathrm{PGF}_{2 \alpha}$ at removal

\begin{tabular}{|c|c|c|c|c|c|c|c|c|}
\hline Variable & \multicolumn{3}{|c|}{ Primiparous } & $P$-value & \multicolumn{3}{|c|}{ Multiparous } & $P$-value \\
\hline Total number & 79 & 77 & & & 139 & 115 & & \\
\hline Proportion synchronized, \% (n) & $77.2(61)$ & $42.8(33)$ & 4.4 & $<0.001$ & $62.5(87)$ & $50.4(58)$ & 1.5 & 0.15 \\
\hline Proportion pregnant, \% (n) & $27.9(17)$ & $45.5(15)$ & 0.5 & 0.09 & $20.6(18)$ & $18.9(11)$ & 1.1 & 0.83 \\
\hline \multicolumn{9}{|l|}{ Cycle $3^{5}$} \\
\hline Proportion pregnant, \% (n) & $36.8(14 / 38)$ & $48.5(17 / 35)$ & 0.6 & 0.27 & $40.8(29 / 71)$ & $27.7(18 / 66)$ & 1.8 & 0.08 \\
\hline Median days from removal ${ }^{4}$ & 65 & 67 & 0.7 & 0.23 & 72 & 72 & 0.9 & 0.52 \\
\hline \multicolumn{9}{|l|}{ Culled } \\
\hline Number culled & 8 & 11 & 0.7 & 0.41 & 24 & 35 & 0.5 & 0.01 \\
\hline Median days at risk ${ }^{4}$ & 320 & 255 & 0.8 & 0.41 & 220 & 191 & 0.8 & 0.23 \\
\hline
\end{tabular}

${ }^{1}$ Odds ratio $(\mathrm{OR})$ generated using the generalized estimating equation to account for the correlation of animals within herd; hazards ratio (HR) generated using the Cox proportional hazard model adjusting the standard error to account for clustering.

${ }^{2}$ Cycle 1 = cows inseminated within $14 \mathrm{~d}$ of device removal.

${ }^{3}$ Cycle 2 = first-insemination cows bred $>14 \mathrm{~d}$ after device removal + second insemination of synchronized cows.

${ }^{4}$ Kaplan-Meier estimate of the median time from device removal.

${ }^{5}$ Cycle 3 = second-insemination nonsynchronized cows + third-insemination synchronized cows. 
45.5, 20.6, and 18.9\% for PRID-treated and control primiparous cows and PRID-treated and control multiparous cows, respectively (Table 2). Multiparous PRIDtreated cows tended to have an increased probability of pregnancy at the second $(P=0.06)$ and third $(P=0.08)$ cycles after device removal (Table 2). Kaplan-Meier estimates of median days from device removal to $\mathrm{AI}$ in the second cycle and third cycle were not different. Similarly, the daily probability of AI was not different between PRID and control cows (Table 2). Multiparous PRIDtreated cows were less $(P=0.01)$ likely to exit the herd not pregnant relative to control multiparous cows. Median number of days at risk of becoming pregnant, however, was not different between PRID and control cows (Table 2).

Time from device removal to pregnancy was reduced by $20 \mathrm{~d}$ in PRID-treated multiparous cows $(67 ; 95 \% \mathrm{CI}=$ 51 to 83 ) relative to multiparous control cows (87; $95 \%$ $\mathrm{CI}=81$ to 127$)$. There was no treatment effect on median time to pregnancy among primiparous cows (PRID $=52$ d; $95 \% \mathrm{CI}=43$ to 76 vs. control $=53 \mathrm{~d} ; 95 \% \mathrm{CI}=30$ to 70). A Cox proportional hazard model was used to investigate the effect of treatment on daily probability of pregnancy. Time to pregnancy was greater $(P<0.001)$ in multiparous cows than primiparous cows. Season, VS, and ketosis in wk 1 or 2 postpartum were not significant in this model. Loss in BCS was not associated with the time to pregnancy. Two-way interactions between treatment and season, VS, and BCS loss were not significant. Similarly, an interaction term was investigated between treatment and ketone status in wk 1 postpartum to further investigate the differential rate of subclinical ketosis in PRID vs. control cows. Again, this interaction term was not significant $(P=0.4)$; however, addition of ketone data to the model increased the hazard ratio for PRIDtreated cows, suggesting that the current estimate may be conservative. Controlling for the impact of clustering at the herd level and parity, progesterone increased the daily probability of pregnancy $(\mathrm{HR}=1.31 ; P=0.01)$. Introduction of a parity $\times$ treatment interaction improved the fit of the model. Daily pregnancy risk in multiparous cows treated with the PRID was increased relative to multiparous control cows ( $\mathrm{HR}=1.53 ; P=0.03$; Table 3; Figure 1). Independent of treatment, primiparous cows became pregnant faster $(P<0.001)$ than multiparous control cows. Evaluation of the independent censoring assumption altered the multiparous PRIDtreated estimated hazard ratio from $1.28(P=0.05)$ to $1.59(P=0.01)$ relative to multiparous control cows. The number of inseminations per pregnancy did not differ between treatment and control cows (2.4 vs. 2.3, respectively; $P=0.64$ ).

\section{DISCUSSION}

The present study is a unique and practical investigation of the impact of a PRID on synchronization of estrus, the probability of pregnancy at first AI, and time from device removal to pregnancy in anestrous lactating dairy cows. Determination of the impact of supplemental progesterone in cows at risk of anovulation can be measured both as short-term and long-term effects. Intravaginal treatment of anovulatory anestrus cows with $1.56 \mathrm{~g}$ of progesterone has been reported to increase circulating progesterone concentrations to a peak of $1.2 \mathrm{ng} / \mathrm{mL}$ within $24 \mathrm{~h}$ and maintain an average serum $\mathrm{P} 4$ concentration greater than $1 \mathrm{ng} / \mathrm{mL}$ for $7 \mathrm{~d}$ (McDougall et al., 2004). Variability in the observed increase in circulating progesterone concentrations can be quite large (Darwash et al., 2001) and is influenced by feed intake and milk production (Lopez et al., 2004; Wiltbank et al., 2006). Of anovular cows responding with increased circulating progesterone, there is an immediate decrease in LH pulse frequency and amplitude (Fike et al. 2004). This decreased circulating LH concentration will result in atresia of the LH-dependent dominant follicle(s) and recruitment of a subsequent follicular wave. In addition to recruitment of a new follicular wave, exogenous progesterone increases estradiol sensitivity of the behavioral centers of the brain, resulting in an increased probability of displayed estrus among treated cows.

Measuring the impact of exogenous progesterone in the long term acknowledges the variability in response to supplemental progesterone and the increased likelihood of an estrus cycle of normal duration and improved hormonal profile after device removal relative to untreated controls. Exogenous progesterone supplemented early in lactation in anovulatory cows failed to initiate cyclicity or decrease days to first ovulation (Nation et al., 2003). Delaying progesterone therapy until after 20 DIM (Darwash et al., 2001), or before first AI (Folman et al., 1990; Rosenberg et al., 1990) repeatedly increased the probability of behavioral estrus at first induced estrus, resulting in improved synchronization and decreased time to pregnancy through altered fertility at the second of 2 induced heats (Rhodes et al., 1999). In the current study, cows were enrolled in a double-blind assignment protocol. Resynchronization treatments were farm-specific and applied to cows diagnosed not pregnant without knowledge of their previous treatment.

Sensitivity, specificity, and predictive values of pedometers for identification of anovular cows have not been published. In the present study, the apparent prevalence of anovulation was approximately $40 \%$. In discussion with the collaborating producers, increased pedometer activity observed before 60 DIM that occurred within 
Table 3. Final Cox proportional hazard model, accounting for the association of animals within herd of the daily pregnancy risk of 410 lactating Holstein cows that failed to display estrus, as measured by pedometry, between 39 and 60 DIM treated with a progesterone-releasing intravaginal device (PRID) or placebo intravaginal device (control) for $7 \mathrm{~d}$ and injected with $\mathrm{PGF}_{2 \alpha}$ at removal

\begin{tabular}{llccccc}
\hline Parity & Treatment & $\mathrm{n}$ & $\begin{array}{c}\text { Time to } \\
\text { pregnancy, }{ }^{1} \mathrm{~d}\end{array}$ & $\begin{array}{c}\text { Hazard } \\
\text { ratio }\end{array}$ & $P$-value & $\begin{array}{c}\text { 95\% } \\
\text { CI }\end{array}$ \\
\hline Primiparous & PRID & 79 & $52^{\mathrm{a}}$ & 1.05 & 0.79 & $0.7-1.5$ \\
& Control & 77 & $53^{\mathrm{a}}$ & Referent & & \\
Multiparous & PRID & 139 & $67^{\mathrm{a}}$ & $\begin{array}{c}1.53 \\
\text { Referent }\end{array}$ & & \\
& Control & 115 & $87^{\mathrm{b}}$ & Re3 & $1.3-2.3$ \\
\hline
\end{tabular}

${ }^{\mathrm{a}, \mathrm{b}}$ Different letters within a column represent a difference using the Wald postestimation test $(P<0.05)$.

${ }^{1}$ Median time (days) from device removal to pregnancy, estimated based on the last recorded insemination before pregnancy diagnosis.

$24 \mathrm{~h}$ after a pen move was deemed a false positive finding; these cows were subsequently eligible for enrollment. This apparent prevalence exceeds the average reported prevalence of delayed resumption of ovarian activity, but is consistent with estimates of the prevalence of abnormal resumption of ovarian activity (Lamming and Darwash, 1998; Opsomer et al., 2000). Thus, cows selected for enrollment in the present study may have included 1) cows that were truly anovulatory, 2) cows that had ovulated without preceding behavioral estrus, and 3) cows that had a prolonged luteal phase (retained corpus luteum) commencing before entering the breeding period at 45 DIM. These 3 potentially different hor- monal patterns have been associated with decreased probability of pregnancy at first $\mathrm{AI}$, and increased time to pregnancy (Lamming and Darwash, 1998).

Progesterone treatment reduced time from device removal to AI by $17 \mathrm{~d}$ in primiparous cows and $8 \mathrm{~d}$ in multiparous cows relative to their parity-specific control herdmates. Survival analysis was used to analyze this variable to appropriately account for cow time at risk in cows that failed to display estrus or that were diagnosed as nonpregnant before culling. Although it is the correct methodology, survival analysis has not routinely been used for analysis of this type of data in the literature, thereby limiting direct comparisons between many pub-

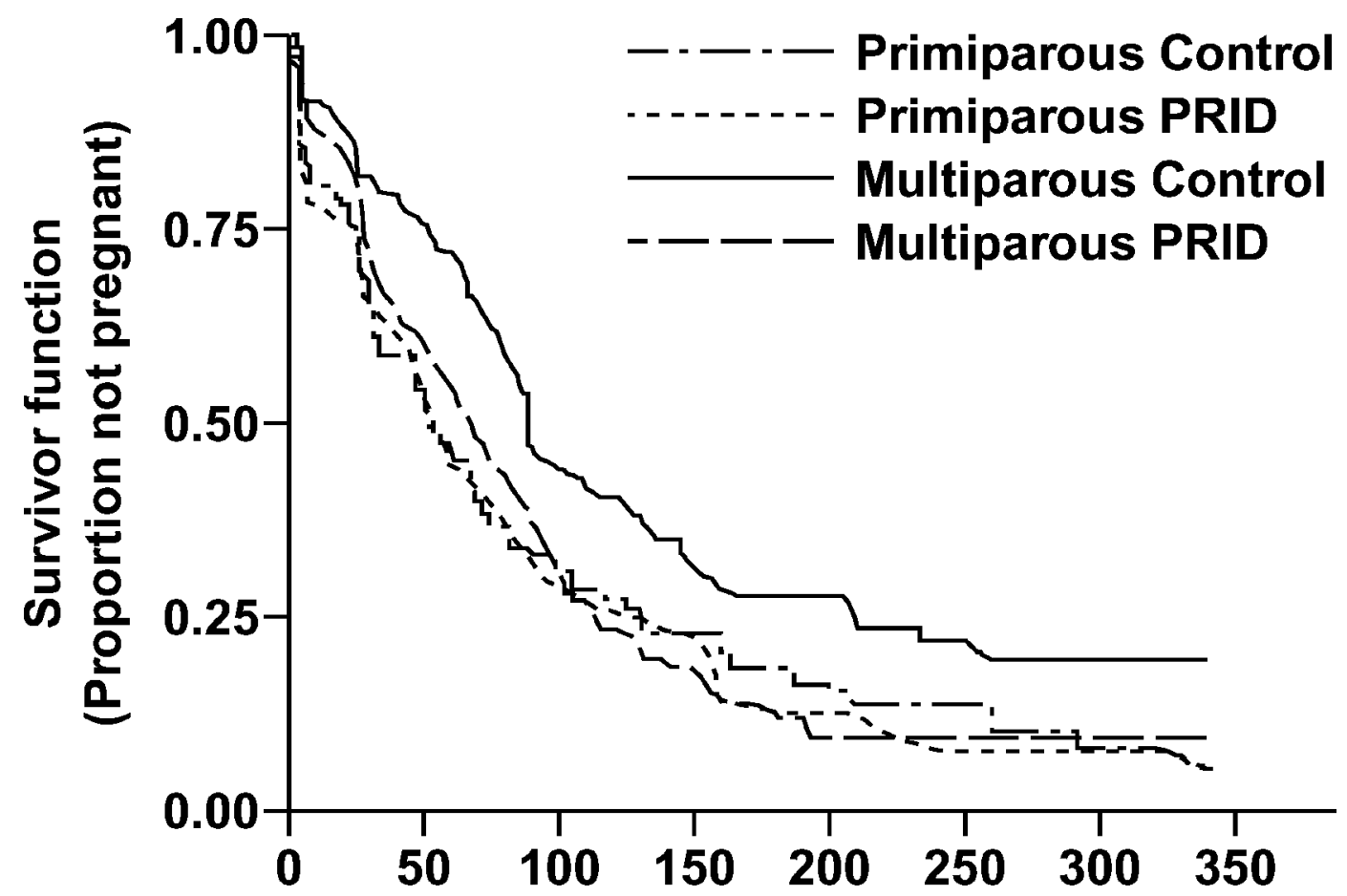

Figure 1. Survival curves of days from device removal to pregnancy in primiparous and multiparous cows not inseminated by 60 DIM, but subsequently treated with a progesterone-releasing intravaginal device (PRID) or placebo intravaginal device (control) for $7 \mathrm{~d}$ and receiving a single dose of $\mathrm{PGF}_{2 \alpha}$ and inseminated after observed estrus. 
lished reports and the current study. Despite this difference, previous research reported a 15-d reduction in the interval from calving to AI with the use of the PRID in fall calving Holstein-Friesian cows inseminated approximately $72 \mathrm{~d}$ postpartum (Drew et al., 1982).

As hypothesized, progesterone-treated cows were more likely to be inseminated within $14 \mathrm{~d}$ after device removal. The efficacy of short-term exposure to exogenous progesterone to synchronize estrus is consistent with other studies (Rosenberg et al., 1990; Lucy et al., 2001). The magnitude of difference in synchronization between primiparous and multiparous cows was unexpected. There is no evidence to support a parity difference in the proportion of anovulatory cows enrolled. Specifically, among control cows, there was no parity-associated difference in the spontaneous rate of return to estrous during the 7-d intravaginal device treatment period (7.1 vs. $5.9 \%$; primiparous vs. multiparous) and, there was no difference in the estrous synchronization rate between control-treated multiparous and controltreated primiparous cows.

Pedometers were used to standardize estrus between farms. Walking activity has been shown to increase gradually from 72 to $16 \mathrm{~h}$ before ovulation, with a sudden increase from $16 \mathrm{~h}$ to standing estrus, followed by an exponential decay with no refractory period postestrus (Arney et al., 1994). Sensitivity (probability that increased walking activity is observed given that the cow subsequently ovulates), and predictive value of increased walking activity are both greater than $80 \%$ in resynchronized heats (Cavalieri et al., 2003). Walking activity is known to decrease with increasing parity, with increasing milk production averaged over the 3-d period immediately before estrus, and during periods of elevated ambient temperature (Lopez et al., 2004; LopezGatius et al., 2005; Wiltbank et al., 2006). The impact of moderate lameness on walking activity measured using pedometers, however, has not been fully investigated. Walking activity of lactating cows whose estrous cycles were synchronized after treatment with $\mathrm{PGF}_{2 \alpha}$ or progesterone $+\mathrm{PGF}_{2 \alpha}$ revealed no differences in the number of steps attributable to treatment (Lopez-Gatius et al., 2005). It has been shown that $\mathrm{PGF}_{2 \alpha}$ administered $24 \mathrm{~h}$ before, or concurrent with progesterone device removal, does not alter the mean time to onset of estrus or ovulation (Hittinger et al., 2004). Furthermore, detection of estrus in beef cows, as well as dairy cows and heifers, was improved in cows with increased progesterone concentrations at $\mathrm{PGF}_{2 \alpha}$ injection (Rosenberg et al., 1990; Lucy et al., 2001). Thus, the smaller proportion of multiparous cows displaying estrus may reflect more apparently silent ovulations. Parity $\times$ progesterone treatment interactions on the proportion of cows inseminated within $28 \mathrm{~d}$ has previously been reported. In contrast, the previous interactions reported that multiparous-treated cows were inseminated earlier than primiparous-treated cows (Rosenberg et al., 1990).

Probability of pregnancy at first AI in the present study (36.1\% primiparous and $23.3 \%$ multiparous) is consistent with other estimates after using progesterone devices and $\mathrm{PGF}_{2 \alpha}$ (Folman et al., 1990; Lopez-Gatius et al., 2005). A parity $\times$ treatment interaction was present in a multivariable logistic regression model of the probability of pregnancy at first AI. Stratification by parity revealed no significant treatment effect on the probability of pregnancy at first AI, independent of time to first AI, relative to the parity-specific controls. Progesterone supplementation has repeatedly shown improved probability of pregnancy at first AI in anestrous cows enrolled in an ovulation synchronization protocol with timed AI and in the treatment of cystic ovarian disease (Folman et al., 1990; El-Zarkouny et al., 2004). To separate the potential impact of subsequent therapy, probability of pregnancy was classified retrospectively based on synchronization response to progesterone. The probability of pregnancy within $14 \mathrm{~d}$ of device removal tended to be greater in control primiparous cows than in PRIDtreated primiparous cows. This difference, although not significant, is attributable to previous cyclic status among control cows displaying estrus after $\mathrm{PGF}_{2 \alpha}$ being more likely to be cyclic at the time of device insertion. Translation of this short-term response to application on a dairy should properly account for the cows at risk of AI. In this situation, the proportion of eligible cows that became pregnant within $14 \mathrm{~d}$ of device removal is 21.5\% (17/79) of PRID-treated primiparous cows and $19.5 \%$ (15/77) of control primiparous cows. There was no difference in the probability of pregnancy among multiparous cows. Progesterone exposure in the current investigation decreased the time from device removal to first AI without reducing the probability of pregnancy at first AI.

Progesterone-treated multiparous cows became pregnant $20 \mathrm{~d}$ earlier than control multiparous cows. Overall reduction in time to pregnancy in multiparous cows was only partially explained by the 8-d reduction in time to first AI. In contrast, Drew et al. (1982) reported a 14$\mathrm{d}$ decrease in calving to conception interval that was completely attributable to decreased days from calving to AI. Figure 1 showed that primiparous cows (independent of treatment) and multiparous PRID-treated cows became pregnant faster than multiparous control cows. The design of this study does not allow for a mechanistic explanation of the improved pregnancy rate. The probability of pregnancy at the second and third cycle starting $14 \mathrm{~d}$ after device removal, however, tended to be greater in the progesterone-treated group. Analysis of time from device removal to $\mathrm{AI}$ in the second cycle and third cycle 
showed no difference in the daily probability of AI. Insemination after the second of 2 induced estrus periods after progesterone synchronization has been shown to increase first-service pregnancy risk (Rhodes et al., 1999). In another study, progesterone-treated anovulatory cows were more likely to have a subsequent luteal phase of normal duration (Fike et al., 1997). Combination of these 2 interventions would provide early AI of PRID-treated multiparous cows, and would result in an improved progesterone profile during the period of follicle development before the second induced ovulation or second observed estrus relative to control multiparous cows. The progesterone profile before AI has been strongly associated with the probability of pregnancy at that service (Cartmill et al., 2003). Although the hormonal profile was not monitored in the present investigation, the increased pregnancy risk might indicate that previous progesterone exposure primed the hypothalamic-ovarian axis, resulting in an improved progesterone profile contributing to the increased fertility.

The discrepancy between primiparous and multiparous cows was unexpected. Previous studies using progesterone devices and observed estrus have reported a reduction in time to pregnancy that is attributable to the reduction in time to first AI (Drew et al., 1982). Other studies have shown no impact on time to pregnancy, but a significant alteration in AI pattern (Folman et al., 1990; Lucy et al., 2001). Lack of reduction in time to pregnancy in primiparous cows may reflect a difference in the rate of return to a predictable ovulatory cycle between control primiparous and multiparous cows.

Device retention rate was $93 \%$ in both groups. This is similar to other large-scale field trials using this progesterone device (Drew et al., 1982). The effect of an intravaginal device on VS relative to a placebo treatment has not previously been reported. In this study, progesterone significantly decreased the risk of copious amounts of vaginal discharge at device removal. This result should be interpreted with caution because of the small number of cows having marked vaginal reaction (VS $=2 ; n=43$ ). Vaginitis assessments have been published for both the PRID and the controlled internal drug release insert (Eazi-Breed CIDR progesterone insert, Pfizer Animal Health, New York, NY) in post-AI applications. A 14-d PRID treatment induced localized vaginitis in approximately $50 \%$ of treated cows without changing the risk of pregnancy (Villarroel et al., 2004). Similarly, 65\% of cows had a mild to moderate vaginal reaction to a 7$d$ exposure period to the CIDR, with $27 \%$ of devices associated with yellow mucus at removal (Chenault et al., 2003). In the present study, VS did not affect pregnancy risk at first service, interval from insertion to AI, or interval from calving to pregnancy. Bulman et al. (1978) cultured low to moderate numbers of nonpatho- genic bacteria after a 14-d PRID treatment in 9 of 10 cows; but no growth was obtained in repeat sampling 7 d later (Bulman et al., 1978). Given the lack of impact on our outcomes of interest, this indicates that no reason likely exists to delay AI in cows displaying estrus based on the condition of the device at removal.

To provide additional information to characterize cows at risk of anovulation, periparturient disease (retained placenta and metritis), milk ketone concentration, and BCS were recorded during the periparturient period. Of these predictors, diagnosis of retained placenta was the sole event that was associated with cows not displaying estrus before 60 DIM. Among enrolled cows, prevalence of metritis and retained placenta did not differ between treatments. An association between retained placenta and delayed resumption of ovarian activity was previously reported (Opsomer et al., 2000). Diagnosis of subclinical ketosis in either the first or second week postpartum was not predictive of failure to display estrus before 60 DIM. Differences between treatment groups in the prevalence of subclinical ketosis and the proportion of cows losing 1 BCS point between calving and treatment were unexpected. Inclusion of subclinical ketosis or BCS loss in the current study did not affect time to pregnancy, and did not alter the effect of treatment.

\section{CONCLUSIONS}

Progesterone supplementation in cows that had failed to display estrus by 60 DIM decreased time to pregnancy. Enrollment of cows based on pedometer activity has not previously been used as a selection criterion. Association between walking activity and ovulatory status of cows before enrollment is unknown; however, the observed difference in estrus-synchronization rates between PRID and control cows indicates that the selected cows were at risk of failure to ovulate. Effect of progesterone on outcomes differed between multiparous and primiparous cows. Time to pregnancy was improved in multiparous cows relative to primiparous cows. This outcome is rarely measured beyond the second cycle in reproductive trials; however, treatment with progesterone is known to significantly improve the conception rate in ovulation synchronization protocols applied to anestrous cows; thus, investigation of the longer term effect of treatment is justified.

\section{ACKNOWLEDGMENTS}

The authors thank Pierre Gadbois and Vétoquinol (Lavaltrie, Quebec, Canada) for funding this research and Schering-Plough Animal Health for in-kind support. We also thank participating veterinarians and producers for their dedication and effort in completing this project. 


\section{REFERENCES}

Arney, D. R., S. E. Kitwood, and C. J. C. Philips. 1994. The increase in activity during oestrus in dairy cows. Appl. Anim. Behav. Sci. 40:211-218.

Bulman, D. C., P. E. McKibbin, W. T. Appleyard, and G. E. Lamming. 1978. Effect of a progesterone releasing intravaginal device on milk progesterone levels, vaginal flora, milk yield and fertility of cyclic and non-cyclic dairy cows. J. Reprod. Fertil. 53:289-296.

Cartmill, J. A., S. Z. El-Zarkouny, B. A. Hensley, G. C. Lamb, and J. S. Stevenson. 2001. Stage of cycle, incidence, and timing of ovulation, and pregnancy rates in dairy cattle after three timed breeding protocols. J. Dairy Sci. 84:1051-1059.

Cavalieri, J., V. Eagles, M. Ryan, and K. L. Macmillan. 2003. Comparison of four methods for detection of oestrus in dairy cows with resynchronised oestrous cycles. Aust. Vet. J. 81:422-425.

Chenault, J. R., J. F. Boucher, K. J. Dame, J. A. Meyer, and S. L. Wood-Follis. 2003. Intravaginal progesterone insert to synchronize return to estrus of previously inseminated dairy cows. J. Dairy Sci. 86:2039-2049.

Darwash, A. O., G. E. Lamming, and M. D. Royal. 2001. A protocol for initiating oestrus and ovulation early postpartum in dairy cows. Anim. Sci. 72:539-546.

Drew, S. B., C. M. Gould, and D. C. Bulman. 1978. The effect of treatment with a progesterone releasing intravaginal device on the fertility of spring-calving Friesian dairy cows. Vet. Rec. 103:259-262.

Drew, S. B., C. M. Gould, P. L. L. Dawson, and J. F. B. Altman. 1982. Effect of progesterone treatment on the calving to conception interval of Friesian dairy cows. Vet. Rec. 111:103-106.

El-Zarkouny, S. Z., J. A. Cartmill, B. A. Hensley, and J. S. Stevenson. 2004. Pregnancy in dairy cows after synchronized ovulation regimens with or without presynchronization and progesterone. J. Dairy Sci. 87:1024-1037.

Ferguson, J. D., D. T. Galligan, and N. Thomsen. 1994. Principal descriptors of body condition score in Holstein cows. J. Dairy Sci. 77:2695-2703.

Fike, K. E., F. N. Kojima, B. R. Lindsey, E. G. M. Bergfeld, J. A. Quintal-Franco, E. J. Melvin, E. L. Zanella, M. E. Wehrman, and J. E. Kinder. 2004. Regulation of frequency of luteinizing hormone pulses by magnitude of acute change in circulating concentration of progesterone of female cattle. Anim. Reprod. Sci. 84:279-291.

Fike, K. E., M. E. Wehrman, E. G. Bergfeld, F. N. Kojima, and J. E. Kinder. 1997. Prolonged increased concentrations of $17 \beta$-estradiol associated with development of persistent ovarian follicles do not influence conception rates in beef cattle. J. Anim. Sci. 75:13631367.

Folman, Y., M. Kaim, Z. Herz, and M. Rosenberg. 1990. Comparison of methods for the synchronization of estrous cycles in dairy cows. 2. Effects of progesterone and parity on conception. J. Dairy Sci. 73:2817-2825.

Geishauser, T., K. Leslie, J. Tenhag, and A. Bashiri. 2000. Evaluation of eight cow-side ketone tests in milk for detection of subclinical ketosis in dairy cows. J. Dairy Sci. 83:296-299.

Gumen, A., J. N. Guenther, and M. C. Wiltbank. 2003. Follicular size and response to Ovsynch versus detection of estrus in anovular and ovular lactating dairy cows. J. Dairy Sci. 86:3184-3194.
Hittinger, M. A., J. D. Ambrose, and J. P. Kastelic. 2004. Luteolysis, onset of estrus, and ovulation in Holstein heifers given prostaglan$\operatorname{din} \mathrm{F}_{2 \alpha}$ concurrent with, or 24 hours prior to, removal of an intravaginal, progesterone-releasing device. Can. J. Vet. Res. 68:283287.

Lamming, G. E., and A. O. Darwash. 1998. The use of milk progesterone profiles to characterise components of subfertility in milked dairy cows. Anim. Reprod. Sci. 52:175-190.

Lopez, H., L. D. Satter, and M. C. Wiltbank. 2004. Relationship between level of milk production and. Anim. Reprod. Sci. 81:209-223.

Lopez-Gatius, F., P. Santolaria, I. Mundet, and J. L. Yaniz. 2005. Walking activity at estrus and subsequent fertility in dairy cows. Theriogenology 63:1419-1429.

Lucy, M. C., H. J. Billings, W. R. Butler, L. R. Ehnis, M. J. Fields, D. J. Kesler, J. E. Kinder, R. C. Mattos, R. E. Short, W. W. Thatcher, R. P. Wettemann, J. V. Yelich, and H. D. Hafs. 2001. Efficacy of an intravaginal progesterone insert and an injection of $\mathrm{PGF}_{2 \alpha}$ for synchronizing estrus and shortening the interval to pregnancy in postpartum beef cows, peripubertal beef heifers, and dairy heifers. J. Anim. Sci. 79:982-995.

McDougall, S., C. W. Compton, and F. M. Anniss. 2004. Effect of exogenous progesterone and oestradiol on plasma progesterone concentrations and follicle wave dynamics in anovulatory anoestrous post-partum dairy cattle. Anim. Reprod. Sci. 84:303-314.

Nation, D. P., C. R. Burke, G. Parton, R. Stevenson, and K. L. Macmillan. 2000. Hormonal and ovarian responses to a 5-day progesterone treatment in anoestrous dairy cows in the third week post-partum. Anim. Reprod. Sci. 63:13-25.

Opsomer, G., Y. T. Grohn, J. Hertl, M. Coryn, H. Deluyker, and A. de Kruif. 2000. Risk factors for post partum ovarian dysfunction in high producing dairy cows in Belgium: A field study. Theriogenology 53:841-857.

Pursley, J. R., M. C. Wiltbank, J. S. Stevenson, J. S. Ottobre, H. A Garverick, and L. L. Anderson. 1997. Pregnancy rates per artificial insemination for cows and heifers inseminated at a synchronized ovulation or synchronized estrus. J. Dairy Sci. 80:295-300.

Rhodes, F. M., B. A. Clark, S. McDougall, and K. L. Macmillan. 1999. Insemination at the second of two induced oestrous periods in anoestrous dairy cows increases conception rates to first service. N. Z. Vet. J. 47:39-43.

Rosenberg, M., M. Kaim, Z. Herz, and Y. Folman. 1990. Comparison of methods for the synchronization of estrous cycles in dairy cows. 1. Effects on plasma progesterone and manifestation of estrus. J. Dairy Sci. 73:2807-2816.

Stata Corporation. 2005. Stata Statistical Software: Release 9.1. Stata Corporation, College Station, TX.

Stevenson, J. S., and A. P. Phatak. 2005. Inseminations at estrus induced by presynchronization before application of synchronized estrus and ovulation. J. Dairy Sci. 88:399-405.

Thatcher, W. W., and C. J. Wilcox. 1973. Postpartum estrus as an indicator of reproductive status in the dairy cow. J. Dairy Sci. $56: 608-610$.

Villarroel, A., A. Martino, R. H. BonDurant, F. Deletang, and W. M. Sischo. 2004. Effect of post-insemination supplementation with PRID on pregnancy in repeat-breeder Holstein cows. Theriogenology $61: 1513-1520$

Wiltbank, M., H. Lopez, R. Sartori, S. Sangsritavong, and A. Gumen. 2006. Changes in reproductive physiology of lactating dairy cows due to elevated steroid metabolism. Theriogenology 65:17-29. 